CULTURA, LENGUAJE Y REPRESENTACIÓN / CULTURE, LANGUAGE AND REPRESENTATION · ISSN 1697-7750 • VOL. XV \2016, PP. 65-80 REVISTA DE ESTUDIOS CULTURALES DE LA UNIVERSITAT JAUME I / CULTURAL STUDIES JOURNAL OF UNIVERSITAT JAUME I

DOI: HTTP://DX.DOI.ORG/10.6035/CLR.2016.15.5

\title{
¿Relatos restaurativos? Acercamiento a las dificultades para construir una memoria compartida sobre ETA y sus víctimas ${ }^{*}$
}

\author{
Restorative accounts? Approaching the difficulties to build \\ a collective memory on ETA and its victims
}

MARTA RODRÍGUEZ FOUZ

UNIVERSIDAD PÚBLICA DE NAVARRA

Recibido: 10-10-2014

Aceptado: 15-03-2015

RESUMEN: El trabajo atiende a las polémicas suscitadas en la construcción del relato sobre ETA y sobre sus víctimas. Se analizan las dificultades y los retos de una gestión institucional de la memoria de la violencia y se advierten las dificultades que afronta una sociedad democrática para alcanzar una convivencia pacífica tras un periodo de enfrentamiento y conflicto violento, atendiendo, en particular, al respeto a la memoria de las víctimas. Para este análisis se presta atención a las divergencias en los relatos, que son percibidos como agravio por parte de las víctimas, y a los intentos institucionales de homenajear a esas víctimas. La Ley 4/2008 de Reconocimiento y Reparación a las Víctimas del Terrorismo, y las iniciativas que se siguen de su implementación, permiten recalar en la dimensión más formal de esa gestión del relato, pero junto a ellas adquieren relevancia las tensiones y vivencias ligadas a revisiones ideológicas sobre la memoria del conflicto y sobre la construcción de una convivencia pacífica. Se trata de estudiar las expresiones colectivas de legitimación y deslegitimación de la lucha armada como muestra de las dificultades para la convivencia cuando se movilizan cosmovisiones dispares acerca del significado de la violencia y de la responsabilidad sobre las víctimas. La mirada hacia esa realidad exige prestar atención a los conceptos que vienen siendo reiterados en la esfera pública como claves para el final de la violencia. La memoria de las víctimas (junto con

* $\quad$ Este trabajo se ha realizado dentro del proyecto «La guerra y sus justificaciones. Tendencias y problemas actuales» (DER2013-47425-R), financiado por el Ministerio de Economía y Competitividad y dirigido por Roger Campione. Además, agradezco la ayuda del grupo de investigación Cambios Sociales de la Universidad Pública de Navarra. 
la problemática definición de víctima) la solicitud de perdón, la política penitenciaria, la reconciliación o la existencia de vencedores y vencidos, entre otros, aparecen como elementos de debate que permiten incidir en el significado y las exigencias de la convivencia democrática y que apuntan hacia la imposibilidad de propiciar una memoria colectiva compartida y un único relato (¿un relato restaurativo?) sobre la existencia de ETA.

Palabras clave: víctimas, relato, memoria, justicia restaurativa, legitimación de la violencia.

ABSTRACT: This paper focuses on the controversies emerged out of the efforts to elaborate the historical narrative on ETA and its victims. Public institutions' challenges and difficulties to manage the collective memory of violence are explored here. In addition, the problems which a democratic society faces to attain a peaceful coexistence after a period of confrontation and violent conflict will be addressed, paying especial attention to the respect for the memory around the victims. In order to do so, the different interpretations that produce unlike narratives and which are considered by some social agents as offenses towards the victims are studied, along with the institutional initiatives to pay tribute to them. The law 4/2008: Terrorism victims' Recognition and Reparations as well as the actions detached from it allow for deepening into this narrative management's most formal dimension; however, they also open the path to analyze the tensions and experiences revolving around them and which are linked to the ideological reviews about both the memory of the conflict and the process of building a peaceful coexistence. Furthermore, the paper explores the legitimizing and delegitimizing collective expressions of the armed struggle, as indicators for the coexistence problems that arise when contrasting worldviews about the meaning of violence and the commitment to the victims are utilized. Looking into this reality demands for an examination of the most salient concepts that are highlighted within the public sphere as the key for the end of violence: the memories of the victims - together with the problematic definition of what a victim is -, the request of asking for pardon, the penitentiary policies, the reconciliation, the existence of winners and loosers, etc. These all are the hot topics of debate which, on the one hand, enable the understanding the meaning of and the exigencies for a democratic coexistence and, on the other hand, point out the impossibility of building neither a shared collective memory nor an only narrative - a restorative narrative - about the existence of ETA.

Keywords: victims, story, memory, restorative justice, legitimization of violence. 


\section{Introducción}

El propósito de este artículo es profundizar en las dificultades para la construcción de un relato sobre la existencia de ETA y su incidencia en la convivencia que pueda ser aceptado por las víctimas como un paso hacia una eventual reconciliación. Han pasado cinco años desde el anuncio de la última tregua y Euskadi parece empezar a coger aire sin miedo a que vuelvan a irrumpir las bombas, los tiros, los secuestros, las amenazas y las extorsiones. Y sin embargo, permanece la tensión sobre cómo gestionar el recuerdo y los efectos de ese pasado reciente. Esta evidencia nos invita a reflexionar sobre la importancia de la memoria y del reconocimiento como una de las claves de la normalización de la convivencia. A partir de ahí, el objetivo de este trabajo es indagar en las dificultades para cohesionar un relato sobre lo sucedido atendiendo a dos ámbitos: el institucional y el de la vida cotidiana. Para ello, tras señalar los estrechos vínculos entre memoria y justicia, se partirá de las iniciativas institucionales de reconocimiento y reparación hacia las víctimas del terrorismo y, en particular, de la Ley 4/2008 aprobada con ese propósito; vinculando esas iniciativas con el núcleo de algunos de los debates que irrumpen en la esfera pública a la hora de reconocer el dolor causado y de deslegitimar definitivamente la violencia. Se trata, en suma, de profundizar en los desafíos para la convivencia que supone la existencia de un pasado sangriento, cuyos efectos aún están muy latentes en las víctimas, en los victimarios y en la sociedad vasca en su conjunto. La posible pertinencia de este enfoque reside en que se considera que la construcción de un relato que integre críticamente lo ocurrido (orientándolo, insisto, hacia la deslegitimación de la violencia) es uno de los pasos inexcusables para poder avanzar hacia una cierta justicia reparadora y, en especial, para incorporar argumentos sólidos contra futuros ejercicios de legitimación de la violencia.

\section{La importancia del relato y su vinculación con la justicia}

Desde hace un tiempo va tomando cuerpo una noción de justicia que trata de ubicar en el centro de su acción a las víctimas. La idea de reparación que incluye, como exigencia para el ejercicio de la justicia, la incorporación del reconocimiento por parte del victimario del daño causado a la víctima, añade una dimensión no contemplada por la justicia penal (salvo como posible atenuante). Esa dimensión incide en la restauración de la convivencia y adquiere todo su sentido en escenarios postbélicos o allá donde la violencia colectiva haya minado las bases de una vida compartida. Esa reinterpretación de la justicia, 
que no se conforma con evitar la impunidad sino que quiere ofrecer la ocasión para restablecer una convivencia rota, se conjuga, ciertamente, en una clave desiderativa que no siempre es bien recibida. No en vano, requiere por parte de la víctima la disposición a reconciliarse eventualmente con el causante de su dolor. ${ }^{1}$ Y además, lo que resulta más complicado, presta oído a las razones que pudiera esgrimir el responsable de ese dolor. Así, los obstáculos son notables, por lo que cuesta no percibir un aliento utópico en la apuesta por la llamada justicia restaurativa. Con todo, no parece insensato dejarse impulsar hacia ese horizonte, aunque genere frustración.

Partiendo de la sintonía con esa perspectiva, resulta interesante enfocar una de las dimensiones más recurrentes cuando se habla de víctimas y de un pasado sangriento: la memoria colectiva; y, en particular, la narración que se despliega desde sus contenidos más identificables. La idea es recalar en la construcción de esa memoria calibrando si tiene sentido (y sirve para algo) movilizarla en la clave restaurativa/reparadora que da aliento a esa otra concepción de la justicia como resultado de interacciones entre sujetos directamente implicados. Se trata de advertir los desafíos que provoca la exigencia de incorporar al presente la memoria de lo sucedido desde esa perspectiva restaurativa $\mathrm{y}$, al tiempo, de medir el valor práctico de ese ejercicio.

La propuesta es establecer un símil entre aquella aspiración a una justicia restaurativa y la construcción de relatos restaurativos, entendiendo que esos relatos soportarían idénticas presiones y asumirían los mismos desafíos que aquella y que, en cierto modo, podrían considerarse episodios esenciales de ese proceso reparador. Desde la perspectiva de las víctimas, la imposibilidad de contar su dolor e identificar a sus ejecutores es percibida como una injusticia que añade sufrimiento a su experiencia (Calleja, 2001; Ezkerra, 2001; Juaristi, 1997). Si al silencio o el ninguneo hacia sus relatos se le suma, además, la justificación de los crímenes que les han convertido en víctimas, la desazón puede ser aún mayor. De ahí que, en la búsqueda de relatos coherentes que cuenten lo ocurrido, la participación de todos los implicados parezca una condición inexcusable. En especial para que irrumpa, desde la evidencia del daño causado, el rechazo contra los procesos de legitimación de la violencia. En otras palabras, para que comparezcan, sin vuelos abstractos ni apuestas ideológicas que des-

1. Atendiendo a esa clave se han venido realizando encuentros «restaurativos» entre presos de ETA y víctimas del terrorismo (Pascual Rodríguez, 2013). Esos encuentros, que se realizan precisando que no reportan beneficios penitenciarios, participan de esa inquietud que, por lo demás, solo ha conseguido involucrar a exmiembros de ETA, en particular a aquellos que han apostado por la llamada Vía Nanclares, que establece unos requisitos muy claros en cuanto al reconocimiento del daño causado y de su injustificabilidad. 
carnen (Ricoeur, 1987), los efectos reales de la apuesta por la violencia como argumentos irrefutables contra ella. En rigor, solo si los ejecutores admitiesen la injusticia radical del daño causado a sus víctimas podría construirse esa memoria restaurativa tan ambiciosa.

En el contexto de Euskadi y de ETA, pueden distinguirse dos momentos muy diferentes en cuanto a la construcción de esa memoria. Uno, cuando el silencio era la respuesta habitual ante los crímenes y la complicidad ideológica (leída en clave de oposición contra los opresores españoles) impedía la emergencia de una oposición social firme y pública. Otro, cuando empiezan a tomar cuerpo movimientos sociales pacifistas que salen a la calle para manifestar su rechazo a la violencia (Zubero, 1998; Funes, 1998; Rodríguez Fouz, 2003 y 2010). A partir de ahí, el apoyo a las víctimas empieza a ser (paulatinamente) parte del relato que pudiera llegar a contarse. No obstante, pese a ese asomo incipiente de rechazo a ETA y de apoyo a sus víctimas, la justificación de sus acciones por parte de una parte considerable de la población, durante esos años y hasta hoy, hace complicado presuponer un auténtico proceso de reconciliación. Mientras el victimario siga justificando (en este caso en clave política e ideológica) sus acciones violentas, difícilmente puede haber cabida al inicio de una convivencia sin resentimientos, rencores y sospechas (algo, por lo demás, que nuevamente se incorpora como expectativa y horizonte utópicos). En el plano de la construcción de relatos restaurativos, esa disonancia genera tensiones evidentes y difícilmente resolubles. La disposición para el encuentro podría parecer incluso un despropósito.

Por lo demás, no debe entenderse que esa aspiración a incorporar relatos restaurativos se anticipa como una narración unilateral, cerrada y monolítica. ${ }^{2}$ Es más, junto a esa exigencia de que los victimarios dejen de matizar los porqués de los muertos, los secuestrados, los extorsionados, los amenazados..., e incluso, de justificarlos, se incorpora la necesidad de recoger, como parte de lo ocurrido, la experiencia de las llamadas «otras» víctimas. En concreto, víctimas de los GAL y de abusos policiales. Esto obligaría también al reconocimiento inequívoco de que esa violencia es injustificable y no debe quedar impune. Con todo, es necesario recoger aquí una diferencia esencial, que no apunta a la evidente equidad del dolor de todas las víctimas, sino a los vínculos entre la

2. Participa, más bien, de una concepción de la memoria como rasgo esencial de nuestra ubicación en el mundo y de nuestra pulsión por la narración como fórmula inexcusable de las tramas vitales que nos vinculan como habitantes de un presente que se repliega y proyecta desde nuestros recuerdos y hacia nuestras esperanzas (Ricoeur, 1987). Algo que requiere también el reconocimiento del papel que debe jugar el olvido en la conformación de las narraciones (Ricoeur, 1999 y 2003). 
existencia de esa violencia y su justificación ideológica: así como en Euskadi sí se ha mantenido durante décadas un apoyo social y una justificación de los crímenes de ETA, no se ha dado, a la vez, una legitimación pública del GAL o de los abusos policiales, lo que sitúa el esfuerzo de deslegitimación en dos planos diferentes. El primero tiene que ver con el reconocimiento de la culpa y la restauración de una convivencia rota; el segundo con las garantías formales que deben exigirse a un Estado de derecho para impedir y castigar esas acciones delictivas e ilegales. No es un asunto menor, pero debería situarse en un momento distinto del relato; no en vano, puede entenderse la desconfianza de las víctimas del terrorismo cuando asisten al ejercicio dialéctico y sistemático de esgrimir esas otras violencias o de apelar al «conjunto de las víctimas de uno y otro signo», obviando que el origen de su victimización (y la justificación de su sufrimiento) es radicalmente distinto, aunque el dolor sea idéntico.

Cabe entender que, sin un reconocimiento explícito, por parte de los ejecutores y de quienes los han arropado ideológicamente, de la ilegitimidad del daño irreversible e irreparable que habrían causado, se disipa la oportunidad para incorporar una suerte de memoria restaurativa que propicie un restablecimiento de la convivencia rota. A día de hoy no hay indicios de que ese ejercicio de reconocimiento se haya dado, ni en ETA, ni en los colectivos que tradicionalmente la han alentado. Se localiza sistemáticamente una apelación a las «víctimas de su lado» que desactiva el necesario ejercicio de autocrítica y de reconocimiento de la injusticia radical de sus acciones y levanta un muro ideológico que pasa de puntillas sobre la inhumanidad de su pasado. Faltaría el esfuerzo sincero en favor de la deslegitimación de la violencia porque no hay una auténtica preocupación por el dolor causado. El velo ideológico sigue propiciando relatos parciales que ponen el acento en los agravios sufridos y pasan de puntillas (cuando pasan) por los cometidos.

El riesgo, en esa encrucijada, es que deje de prestarse la necesaria atención a una de las principales causas de la reproducción de la violencia terrorista: la potencia cegadora de la ideología que la anima, y la capacidad de esa ideología para penetrar en el tejido convivencial y hundir nuestro suelo ético. La tragedia de la sociedad vasca no puede resolverse sin una revisión profunda de las complicidades y alientos que han mantenido vivo el conflicto en clave armada. Y sin la asunción de las responsabilidades que se derivan de la posición que habría ocupado cada uno a título individual, pero también colectivamente. Por eso, recordando lo que ha ocurrido en Euskadi en los últimos cuarenta años, resulta inquietante que la izquierda abertzale saque pecho arrogándose el protagonismo y el mérito en la construcción de la paz. Todo ello, además, sin haber mostrado la menor conmoción por los cadáveres ajenos dejados en el ca- 
mino. Es ahí donde la aspiración a un relato restaurativo topa con su obstáculo más monolítico, y donde se evidencia la ausencia de un auténtico ejercicio de reconocimiento hacia las víctimas. Quiere seguirse contando el relato en términos bélicos porque esa lectura exime de responsabilidades morales y apunta como causa de los asesinatos, los secuestros, las agresiones, las extorsiones, las amenazas, etc., al contexto político y no a un posicionamiento moral que interpelaría a los ejecutores como responsables de sus acciones. La cobertura ideológica (esa que vincula aspiraciones políticas y derecho a la violencia) es esencial, y sin el esfuerzo por desmontarla el relato que acaba contándose es inexacto, parcial y alejado de cualquier aspiración a una memoria restaurativa, así como, por supuesto, a una justicia restaurativa (centrada en este caso en la dimensión del reconocimiento del pasado).

Con todo, la indicación sobre la inexistencia de ese relato que podría restaurar la convivencia dañada no impide que se reconozca una mejora sustantiva en la situación actual de Euskadi, algo que puede apreciarse en la pérdida de protagonismo de ETA y en las iniciativas institucionales cuyo propósito declarado es, precisamente, reconocer y reparar el daño causado a las víctimas del terrorismo.

\section{2. ¿Y para qué recordar? El valor de la memoria}

Pero antes de desplegar los argumentos hacia esa dimensión institucional de la gestión del reconocimiento hacia las víctimas, conviene explicitar el porqué de esa importancia otorgada a la memoria colectiva. Es ahí donde nos topamos con la experiencia de las propias víctimas y su necesidad de que se recuerde aquello que las ha convertido en víctimas (Agamben, 2000; Amery, 2001; Etxeberría, 2007). Desde esa reivindicación habitual, se hace evidente que la impunidad no se resuelve únicamente con el encausamiento de los culpables y con la aplicación del código penal. ${ }^{3}$ Se solicita también que no se olvide el daño causado. En otras palabras, que desde el presente se incorporen relatos veraces sobre lo ocurrido, esto es: relatos que recojan lo sucedido explicitando también los silencios, las complicidades y las justificaciones de las que se habría ido derivando la fortaleza de los victimarios. Esa exigencia entronca, en parte, con la propuesta de Reyes Mate sobre una justicia anamnética, que concibe como la única capaz de reparar a las víctimas de la historia

3. Algo que sigue sin cerrarse dados los numerosos asesinatos de ETA sin resolver (Calderín, 2014). 
(Reyes Mate, 2006 y 2008). Según lo entiende Mate, una auténtica memoria de la culpa, dirigida a restaurar la justicia, estaría obligada a convertir las expectativas frustradas de las víctimas injustamente aniquiladas en los proyectos del presente: solo así podría aspirarse a hacer justicia a los vencidos (Reyes Mate, 1991). Así, el recuerdo de su victimización se materializaría en las generaciones vivas como advertencia sobre los límites de su aspiración a la justicia: el presente no podría considerarse justo sin recuperar los proyectos de los vencidos injustamente.

En el caso de ETA y de sus víctimas, cuesta hacer una traslación directa de ese propósito, en concreto porque resulta imposible identificar una aspiración homogénea que compartieran como víctimas. ${ }^{4}$ De ahí, por ejemplo, que cuando las instituciones toman la iniciativa para tratar de rescatar el recuerdo de esas víctimas, el vínculo que se establece entre ellas apunta a una referencia genérica: la de su condición de ciudadanos de un Estado democrático de derecho. ${ }^{5}$ Algo, por otra parte, que adquiere todo su sentido desde la perspectiva que apunta a ETA como causante de una ruptura de la convivencia que no puede justificarse, en ningún caso, desde sus reivindicaciones políticas o desde su lectura ideológica respecto de la supuesta opresión histórica del pueblo vasco (Azurmendi, 1998; Reinares, 2001). La identificación genérica de las víctimas de ETA como ciudadanos, apuntando que su significado político exige el reconocimiento social de su ciudadanía, ${ }^{6}$ permite rescatar aquella clave anamnética sin matizar su sentido por el riesgo de hipotecar las aspiraciones del presente a cuenta de las víctimas del pasado. No en vano, resulta obvio que a las víctimas del terrorismo lo único que les une como colectivo (política y socialmente) es haber sufrido un ataque por parte de un grupo terrorista. De ahí que la construcción de la memoria sobre esa victimización no quepa llevarla a cabo como relato de una reivindicación política o de defensa de unos ideales concretos. ${ }^{7}$ Ni mucho menos, como aliento para incorporar la justicia sobre sus proyectos frustrados. Salvo como esa invitación inconcreta (aunque comprometedora e

4. Puede apreciarse esa diversidad en la crónica de todos los crímenes de ETA recogida en Alonso, Domínguez y García Rey, 2010.

5. Ley 4/2008, de 19 de junio, de Reconocimiento y Reparación a las Víctimas del Terrorismo, Artículo 8.2., BOPV no 124 (1 de julio de 2008): 17323.

6. Ibid.: 17325.

7. En consonancia con esa advertencia puede formularse la incómoda pregunta sobre el porqué del protagonismo político adquirido por determinadas asociaciones de víctimas. Parece olvidarse que no conforman un sujeto político identificable que pudiera articular una voz unitaria acerca, por ejemplo, de las políticas penitenciarias o del endurecimiento del Código Penal. Véase (Rodríguez Fouz, 2010: 21-25). 
ineludible) a restablecer la convivencia sobre la base del respeto a la ciudadanía.

La importancia de la memoria se explicita también en conexión con la idea de que la historia podría funcionar como magistra vitae. Se trataría, desde la conciencia acerca de los desmanes e injusticias del pasado, de aprender a no repetirlos (Cruz, 2005). Se concibe que el conocimiento de la historia, en sus episodios más dramáticos, pudiera propiciar un presente menos bárbaro o menos injusto. En otras palabras, se presupone que el recuerdo del dolor injustamente provocado conduciría a evitar que vuelvan a producirse rupturas de la convivencia similares a las sufridas en ese pasado, de ahí que la mencionada Ley 4/2008 apunte:

Queremos recordar a quienes más han sufrido para que la historia, nuestra historia, no se repita. El reconocimiento a las víctimas del terrorismo es, en consecuencia, no solo un acto de justicia sino la expresión sincera de una sociedad que no quiere revivir nunca más el sufrimiento injusto que aquellas han padecido (BOPV, $\mathrm{n}^{\circ}$ 124: 17309).

Sin necesidad de entrar en las limitaciones de esa proyección que rescata la historia como relato teleológico, pueden apreciarse las virtudes de ese reconocimiento. El relato que recuerda a esas víctimas se pondría al servicio de una invitación a la cautela frente a proyectos totalitarios o que se sustantivan por medio de la violencia, ${ }^{8}$ e impactaría de lleno contra la línea de flotación de los procesos de legitimación de la violencia, cualesquiera que estos fueran. No es necesario confiar en que el conocimiento de ese pasado injusto, generador de víctimas inocentes, vaya a impedir futuras situaciones de violencia colectiva legitimadas ideológicamente para considerar que ese esfuerzo en visibilizar una historia brutal y dolorosa puede contribuir a mejorar la convivencia. Desde la perspectiva de las víctimas resulta evidente, pero también desde el punto de vista de quienes han justificado las acciones de ETA y del de quienes han mirado hacia otro lado o no se han sentido implicados ni conmovidos. ${ }^{9}$ Durante las últimas décadas, desde el primer atentado mortal de ETA, la convivencia en

8. De manera similar a como Todorov refleja la crónica del siglo xx en su Memoria del mal. Tentación del bien (Todorov, 2002); o a como Glucksmann nos advierte sobre la necesidad de ponernos de acuerdo sobre el mal que podemos provocar antes de sobre el bien al que pretendemos aspirar, o, en otras palabras, sobre la necesidad de apostar por una ética que se apoye en la conmoción y no en las convicciones (Glucksmann, 1993: 10).

9. Puede rescatarse aquí la clave de la ética del recuerdo propuesta por Margalit como clave para superar nuestra indiferencia natural frente a los demás (Margalit, 2002: 29). 
Euskadi se ha visto profundamente dañada. Ha faltado acogimiento y sensibilidad hacia las víctimas y ha faltado la condena inequívoca y tajante contra las acciones terroristas. Aunque no sea necesario llegar a la acusación de un silencio culpable que convertiría al conjunto de la sociedad vasca en cómplice del mal por consentimiento (Arteta, 2010), cabe incidir en la necesidad de reconocer esa insensibilidad social como paso previo para restaurar la convivencia. El relato sobre ese pasado exige, por lo tanto, la constatación de que ese silencio ha existido, de que ETA ha contado con un apoyo social que explica en buena parte su longevidad, y que la sociedad vasca ha tolerado y propiciado una legitimación de su lucha armada que complica la narración y que exige la incorporación de estos elementos de la trama si se pretende aprovechar la memoria para impulsar una convivencia no resentida.

\section{Iniciativas institucionales. El esfuerzo por reconocer y reparar. Y, de paso, deslegitimar el terrorismo}

La mencionada Ley 4/2008 nace con una vocación clara de restablecer la convivencia partiendo de la sensibilidad hacia el dolor causado por el terrorismo. En su artículo 8.1 recoge un propósito inequívoco y directamente vinculado con esa vocación: «los poderes públicos vascos promoverán el asentamiento de una memoria colectiva que contribuya a la convivencia en paz y libertad y a la deslegitimación total y radical de la violencia», ${ }^{10}$ algo que enlaza con la prolija exposición de motivos, donde precisamente la memoria comparece como la espina dorsal de todo su articulado.

La aspiración es poner las medidas para que se cumpla el propósito de que «el futuro de nuestra convivencia [sea] construido ineludiblemente sobre la memoria a las víctimas». ${ }^{11}$ La sensibilidad que sitúa en el centro esa memoria se hace eco de un diagnóstico sobre lo sucedido que insiste en la necesidad de:

Compensar, en la medida de lo posible, los olvidos, la invisibilidad y la incomprensión que las víctimas del terrorismo han sentido y sufrido durante muchos años, sin olvidar las situaciones generadas por actos como los de exaltación pública de aquellos que fueron sus victimarios (BOPV, $\mathrm{n}^{\circ} 124$ : 17310).

10. Bopv n ${ }^{\circ} 124$ (1 de julio de 2008): 17325.

11. Ibid.: 17309. 
Ese ejercicio, que incide de lleno en la importancia de la memoria colectiva a la hora de construir la convivencia, se ha ido concretando en diversas iniciativas que han tratado de promover la empatía hacia las víctimas. Así, desde la aprobación de esta ley, y tratando de cumplir sus preceptos, se han realizado homenajes a las víctimas, se han inaugurado monumentos conmemorativos que recuerdan su sacrificio, se han diseñado y aplicado planes educativos para la paz y la convivencia y se han perseguido e impedido «actos efectuados en público que entrañen descrédito, menosprecio o humillación de las víctimas o de sus familiares, exaltación del terrorismo, homenaje o concesión pública de distinciones a los terroristas», ${ }^{12}$ además de actuar contra las pintadas y carteles que promueven esa exaltación y reconocimiento hacia los miembros de ETA (Rodríguez Fouz, 2010).

Puede señalarse, como sintomático de la ruptura de la convivencia que trata de suturarse, que la aplicación de medidas encaminadas a cumplir ese propósito de defensa de la dignidad de las víctimas (artículo 4) ha encontrado resistencias llamativas e ilustrativas de esa disonancia a la hora de explicar lo sucedido en Euskadi. En concreto, y por seleccionar uno de los muchos ejemplos posibles, que entronca, además, con la articulación de la vida cotidiana, podemos fijarnos en uno de sus flancos más ambiciosos: los planes educativos.

El Plan vasco para la paz y los derechos humanos (2008-2011), que fue reformulado en el plan de convivencia democrática y deslegitimación de la violencia (2010-2011) y que ha sido sustituido por el Plan de paz y convivencia (2013-2016), recala en la necesidad de incorporar a las aulas testimonios de las víctimas como clave para sensibilizar contra la violencia. ${ }^{13}$ Uno de los debates más significativos es aquel que se centra en quiénes tendrían que prestar su testimonio. En ese debate llama la atención, por ejemplo, que se llegara a plantear, por parte de partidos nacionalistas vascos, la presencia de víctimas de la violencia de género, algo que podría encajar con un plan de convivencia pero que desvirtúa y diluye el propósito de la ley de reconocimiento y reparación a las víctimas del terrorismo. También ha sido polémica, aunque ha acabado aceptándose, la presencia de víctimas del GAL o de grupos de extrema derecha (BVE). La penúltima tensión se ha producido con la propuesta por parte del Gobierno vasco de que se añadan los testimonios de víctimas de abusos

12. Bopv no 124 (1 de julio de 2008): 17323.

13. Puede verse el interesante trabajo que recoje la experiencia en las aulas de Arana, 2012. Aunque cabe señalar también que no son muchos los centros que han decidido acoger esas visitas. 
policiales. ${ }^{14}$ Se localiza en esas reinterpretaciones del espíritu de la norma un enfrentamiento no resuelto sobre la definición del conflicto vasco. Esas tensiones encuentran su razón de ser principalmente en la ausencia de una condena pública de la violencia terrorista por parte de quienes verbalizan habitualmente y con mayor ahínco la defensa de los derechos de los presos vascos y el reconocimiento hacia las víctimas de abusos policiales o del GAL. Es muy significativo que, desde esos colectivos, junto a la ausencia de ejercicios de deslegitimación de la violencia de ETA y de reconocimiento de la injusticia de sus acciones, se reclame continuamente la atención hacia esas otras víctimas.

Muchas de las víctimas de ETA perciben en esas polémicas una apuesta por la equidistancia y la neutralidad que provoca un cierre en falso del relato sobre lo sucedido. No solo no se habría producido la necesaria autocrítica por parte de los victimarios, con el consiguiente reconocimiento por el daño causado y la asunción de su responsabilidad, sino que, además, se continuaría insistiendo en la versión de la existencia de ETA como consecuencia de un conflicto político y social no resuelto que contribuyó a legitimarla. Insistir, como hace con particular empeño la izquierda abertzale, en el conjunto de las víctimas (las de uno y otro lado), contribuye a perpetuar una lectura perversamente ideológica que mantiene sus eufemismos habituales y su codificación de la historia de ETA en clave bélica. Puede entenderse que, desde la perspectiva de sus víctimas, esa lectura resulte inadmisible y dinamite la posibilidad de una convivencia restaurada.

En rigor, a la hora de hablar de las víctimas, un posicionamiento equidistante y neutral (supuestamente imparcial) resulta ignominioso e injusto: pone al mismo nivel de responsabilidad a las víctimas de ETA en conjunto y a aquellos de sus victimarios que también se habrían convertido en víctimas (del GAL, de la policía, de grupos de extrema derecha o de sus propias acciones terroristas). Cuando se insiste en equiparar a las víctimas englobándolas a todas bajo el nombre de «víctimas de motivación política» se difuminan los perfiles que permiten describir más fielmente lo ocurrido en Euskadi y se produce una conmoción en las víctimas de ETA. Es una equiparación injusta. Máxime cuando no se habría producido en ningún momento el necesario ejercicio de reconocimiento inequívoco de la ilegitimidad de todas las acciones de ETA. Ese sería el auténtico esfuerzo restaurativo que podría restablecer la convivencia rota: sin el reconocimiento de la responsabilidad en la crónica sanguinaria de

14. «Euskadi suma las víctimas policiales a los testimonios en los colegios»: http://politica. elpais.com/politica/2014/02/04/actualidad/1391547914_17562. Consultado el 10 de febrero de 2015. 
ETA de sus actores y de quienes les alentaron, la reparación es imposible. Y lo cierto es que no se perciben signos de esa revisión crítica del pasado. El problema no es reconocer también el dolor de esas otras víctimas (y la injusticia de la violencia ejercida contra ellas), sino la constatación de que esas reivindicaciones llegan sin que se haya dado el paso inequívoco contra la legitimación de la violencia terrorista.

Se trata, en todo caso, de no olvidar que el objetivo de esos planes institucionales de convivencia es deslegitimar la violencia, entendiendo que, durante décadas, no se habría producido un esfuerzo en esa dirección y habiéndose constatado un apoyo por parte de un porcentaje significativo de la juventud vasca $(15 \%)$ a justificar acciones violentas como medio para lograr fines políticos (Informe Extraordinario del Ararteko, 2009: 372). De ahí que a priori puedan llamar la atención esos esfuerzos políticos para añadir otros testimonios, aparte de los de las víctimas de ETA, pues en Euskadi no se habría dado ningún proceso de legitimación social de la violencia policial, o de los GAL, que justificara los esfuerzos institucionales para combatirla.

En cualquier caso, se localiza una tensión no resuelta que comparece públicamente en cuanto las instituciones promueven medidas derivadas de aquella ley, algo que resulta aún más evidente cuando se recala en los debates abiertos en la calle y que conforman el día a día de la gestión pública del recuerdo sobre lo sucedido. Hay múltiples frentes abiertos que merecerían una consideración pausada y profunda. Entre ellos, la consideración sobre si ha de insistirse en la idea de un final con vencedores y vencidos, si tiene sentido la solicitud de perdón, o por qué escuece tanto (y se hace tanto esfuerzo por) la búsqueda de similitudes entre otros contextos de violencia (Irlanda, sobre todo, pero también Palestina, como enseñas de la izquierda abertzale) y el caso vasco... Aquí no hay sitio para prestarle la necesaria atención, pero sí para indicar, como una realidad que hay que tener en cuenta a la hora de comprender las enormes dificultades para ponerse de acuerdo en el suelo ético, la resistencia de algunos sectores de la sociedad vasca a redefinir el significado de ETA y a aceptar, con todas sus consecuencias, su responsabilidad. ${ }^{15} \mathrm{O}$ lo que es lo mismo, a participar en la elaboración de relatos restaurativos.

15. Valgan como ejemplo las recientes declaraciones del Colectivo de Presos Vascos (EPPK), rechazando participar en ninguna iniciativa que contemple como requisitos para la obtención de beneficios penitenciarios el arrepentimiento o el esclarecimiento de atentados, que verbalizan como «delación» de compañeros (Diario de Noticias, 10 de enero de 2015). 


\section{Conclusiones}

Hasta aquí hemos reclamado la importancia de la memoria y del recuerdo de las víctimas como elementos imprescindibles para la construcción de una convivencia no resentida. Se ha incidido, en particular, en cómo el relato sobre un pasado doloroso podría incorporarse en una clave restaurativa (similar a la de la justicia restaurativa) que requeriría la participación de los victimarios y la ineludible asunción de su responsabilidad. El caso de ETA pone en evidencia las enormes dificultades para avanzar en ese relato, pese a que las instituciones vengan forzándose a activar procesos de deslegitimación del terrorismo vinculados, entre otras iniciativas, a revisiones autocríticas del pasado.

La apuesta por relatos restaurativos que vayan en esa dirección se resuelve como interrogante que duda sobre la posibilidad de construir una memoria colectiva que incorpore el reconocimiento por parte de los victimarios de la injusticia radical de sus acciones. El sentido de esa apuesta es el de desactivar los procesos de legitimación ideológica de la violencia: tanto a la hora de vencer la tentación de narrar como épica lo que ha sido una dolorosísima tragedia, como a la hora de proyectar futuros que se escribirían con la sangre del presente. Resulta difícil confiar en que ese propósito se cumpla, pero, en cualquier caso, como ocurre con las utopías no cegadoras, parece sensato orientarse hacia ese horizonte: si perdemos la expectativa de medirnos con cierta idea de justicia, perdemos también la posibilidad de juzgar como injustas las acciones que la quiebran. Desde ahí, la pregunta que podría hacerse es la siguiente: ¿Sería posible que la memoria sobre la convivencia en Euskadi mientras ha existido ETA incorpore el reconocimiento de la ilegitimidad de su apuesta por la lucha armada? Y de paso, ¿el reconocimiento de que todas sus acciones han sido injustas? En la medida en que la respuesta siga siendo, como es, que no, la posibilidad de un relato restaurativo se pierde en el horizonte, marcando el signo de nuestra derrota en la afirmación de una convivencia normalizada o reconciliada.

Quizá, estando donde estamos, tenga más sentido práctico, animados por la búsqueda de una dignificación del recuerdo y del significado de las víctimas, ahondar en el valor de «conservar viva la memoria del pasado, no para pedir una reparación por el daño sufrido sino para estar alerta frente a situaciones nuevas y, sin embargo, análogas» (Todorov, 2000: 58), para, en definitiva, poner el pasado al servicio del presente, y la memoria y el olvido al servicio de la justicia, entendiendo por principio que la responsabilidad sobre lo ocurrido no está repartida a partes iguales y que el primer paso para considerarse artífices 
de la paz sería reconocer retrospectivamente la ilegitimidad de ETA y la injusticia de todas sus acciones.

\section{Referencias bibliográficas}

Agamben, G. (2000): Lo que queda de Auschwitz. El archivo y el testigo, Valencia, Pre-Textos.

Alonso, R.; F. Domínguez; M. García Rey (2010): Vidas rotas. Historia de los hombres, mujeres y niños víctimas de ETA, Madrid, Espasa.

AмÉRy, J. (2001): Más allá de la culpa y la expiación. Tentativas de superación de una víctima de la violencia, Valencia, Pre-Textos.

Arana, R. (2012): Las víctimas en la Educación Vasca. Un testimonio de valor, San Sebastián, Servicio Central de Publicaciones del Gobierno Vasco, recuperado de: www.ikastea.hezkuntza.net.

Arteta, A. (2010): Mal consentido. La complicidad del espectador indiferente, Madrid, Alianza.

Azurmend, M. (1998): La herida patriótica, Madrid, Taurus.

CalleJa, J. Ma (2001): ¡Arriba Euskadi! La vida diaria en el País Vasco, Madrid, Espasa.

Calderín, J. F. (2014): Agujeros del sistema. Más de 300 asesinatos de ETA sin resolver, Vitoria, Ikusager.

Cruz, M. (2005): Las malas pasadas del pasado. Identidad, responsabilidad, historia, Barcelona, Anagrama.

Eguiguren, J.; L. Rodríguez Aizpeolea (2011): eta. Las claves de la paz. Confesiones del negociador, Madrid, Aguilar.

EtXeberRia, X. (2007): Dinámicas de la memoria y víctimas del terrorismo, Bilbao, Bakeaz.

Ezkerra, I. (2001): Estado de excepción. Vivir con miedo en Euskadi, Barcelona, Planeta.

FunES, Ma J. (1998): La salida del silencio. Movilizaciones por la paz en Euskadi. 1986-1998, Madrid, Akal.

Glucksmann, A. (1993): El undécimo mandamiento: ¿es posible ser moral?, Barcelona, Ediciones 62.

JuARISTI, J. (1997): El bucle melancólico. Historias de nacionalistas vascos, Madrid, Espasa-Calpe.

Juntas Generales de Guipúzcoa (2010): Hutsuneak/Vacios, Azpeitia, Gráficas Zubi. 
Bopv (2008): Ley 4/2008, de 19 de junio, de Reconocimiento y Reparación a las Víctimas del Terrorismo (BOPV, $n^{\circ} 124$, martes 1 de julio de 2008).

Margalit, A. (2002): Ética del recuerdo, Barcelona, Herder.

Pascual Rodríguez, E. (coord.). (2013): Los ojos del otro. Encuentros restaurativos entre víctimas y exmiembros de ETA, Santander, Salterrae.

ReINARES, F. (2001): Patriotas de la muerte. Quiénes han militado en ETA y por qué, Madrid, Taurus.

Reyes Mate, M. (1991): La razón de los vencidos, Barcelona, Anthropos.

- (2006): Medianoche en la historia, Madrid, Trotta.

- (2008): Justicia de las víctimas: terrorismo, memoria, reconciliación, Barcelona, Anthropos.

Ricoeur, P. (1987): Tiempo y narración I. Configuración del tiempo en el relato histórico, Madrid, Ediciones Cristiandad.

- (1989): Ideología y utopía, Barcelona, Gedisa.

- (1999): La lectura del tiempo pasado: memoria y olvido, Madrid, Universidad Autónoma de Madrid.

- (2003): La memoria, la historia, el olvido, Madrid, Trotta.

Rodríguez Fouz, M. (2003): Pasiones discursivas. Desafíos de la reflexión sociológica, Pamplona, Universidad Pública de Navarra, 203-48.

- (2010): «Batallas simbólicas. La lucha por el espacio público en Euskadi», Papeles del Ceic, 59, recuperado de: http://www.identidadcolectiva.es/ pdf/59.pdf.

Sontag, S. (2003): Ante el dolor de los demás, Madrid, Alfaguara.

Todorov, T. (2000): Los abusos de la memoria, Barcelona, Paidós.

- (2002): Memoria del mal, tentación del bien. Indagación sobre el siglo XX, Barcelona, Península.

Uribe, W. (2011): Allí donde ETA asesinó, Barcelona, Los libros del lince.

Zubero, I. (1998): «Movilización social y realidad política en el País Vasco», Cuadernos de Alzate, 18: 107-122. 